\title{
PLURALISMO LÓGICO E EPISTEMOGRAFIA INTERATIVA COMO FERRAMENTAS DESCLASSIFICADORAS DO CONHECIMENTO
}

\section{LOGIC PLURALISM AND INTERACTIVE EPISTEMOGRAPHY AS TOOLS FOR THE DEQUALIFICATION OF KNOWLEDGE}

\author{
Maria Sueny Barbosa Soares ${ }^{1}$ \\ Mariana Thamires Martin ${ }^{2}$ \\ Marivalde Moacir Francelin ${ }^{3}$
}

\begin{abstract}
RESUMO: Diante dos novos parâmetros informacionais e suas estruturas de rede, surgem novas oportunidades de comunicação, acesso e participação, fazendo emergir não só do entorno digital como também dos tradicionais ambientes de rede o que poderíamos chamar de exomemórias. Onde há memória, há também necessariamente a organização dessa memória. Usando os sistemas de classificação vigentes teríamos uma organização (des)fragmentada, o que implicaria na perda de alguns desses fragmentos. Assim, é necessário retomar o debate sobre a classificação, visando não só esses novos ambientes, mas também seu antigo caráter epistemológico, trazendo à tona o novo conceito de desclassificação e os princípios da lógica paraconsistente.
\end{abstract}

Palavras-chave: Organização do conhecimento. Classificação. Exomemória. Desclassificação. Lógica paraconsistente.

ABSTRACT: With the new parameters and their network structures, there are new opportunities for communication, access and participation, bringing out not only the digital environment as well as traditional network environments what we might call 'exomemórias'. Where there is memory, there is necessity also the organization of this memory. Using the existing classification systems would have an organization (un)divided, which would imply the loss of some of these fragments. Before it sees necessary to return the debate about the classification, not only direct for these new environments, but also the old epistemological, bringing forth the new concept of declassification and the principles of paraconsistent logic.

Keywords: Knowledge organization. Classification. Exomemória. Declassification. Paraconsistent logic.

\footnotetext{
${ }^{1}$ Graduanda em Biblioteconomia da UFPE. Recife, PE, Brasil. E-mail: tout court@hotmail.com

${ }^{2}$ Graduanda em Biblioteconomia da UFPE. Recife, PE, Brasil. E-mail: mariana-thamires@ @otmail.com

${ }^{3}$ Professor do Departamento de Biblioteconomia e Documentação. ECA/USP; São Paulo, SP, Brasil. E-mail: mfrancelin@yahoo.com.br

\begin{tabular}{|l|l|l|l|l|l|l}
\hline (C) Rev. digit. bibliotecon. cienc. inf. & Campinas, SP & v.11 & n.1 & p.55-71 & jan./abr. 2013 & ISSN 1678-765X \\
\hline
\end{tabular}
}




\section{INTRODUÇÃO}

A sociedade da informação traz à tona um novo espaço transdisciplinar capaz de facilitar o processo de comunicação, intercâmbio de informações e de memórias. Ele atuaria de forma democrática e prática conforme os desejos de seus usuários. Contudo, é necessário pensar de que maneira esse conteúdo disponível está sendo organizado, como poderá ser recuperado e em quais estruturas ele se manterá.

Seguindo essa questão inicial encontra-se na literatura das Ciências Humanas e Sociais discussões sobre o problema do avanço do conhecimento, onde a objetividade ou a legitimidade das ciências exatas e naturais, geralmente dominantes no mundo científico, são questionadas.

No campo da Ciência da Informação, são abordadas questões sobre a categorização excessiva, presente nas classificações, a partir da perspectiva crítica da lógica tradicional. García Gutiérrez (2006; 2007; 2008; 2011) é um dos autores que defende, com base em Edgar Morin, Boaventura de Sousa Santos, Clifford Geertz, Néstor García Canclini, Walter Mignolo e Newton Carneiro Affonso da Costa, a noção de pluralismo lógico diante de uma ação desclassificatória do conhecimento e dos saberes.

A epistemografia interativa é proposta por García Gutiérrez como uma provável solução para alcançar categorias suficientemente complexas e que possam abranger uma estrutura de conhecimento multicultural. Tais categorias, seguindo o conhecimento que pretendem abarcar, também deveriam estar baseadas em uma lógica dinâmica e plural que permitisse rever algumas barreiras epistemológicas que anulam os conhecimentos e os saberes paralelos.

\section{PLURALISMO LÓGICO: O MODELO DOMINANTE E A COSMOVISÃO}

Em princípio, o conhecimento atua seguindo uma lógica racional que utiliza algumas ferramentas associativas, hierárquicas e disjuntivas, formando um sistema de classificação mental. Assim, de acordo com García Gutiérrez (2007, p.5), "Conocemos mediante una acción clasificatoria.”, ou seja, "Conhecer significa dividir e classificar para depois poder determinar relações sistemáticas entre o que se separou” (SANTOS, 2010, p.28).

Quando se está diante de algo novo é quase inevitável usar classes e/ou representações. Durante o processo de classificar e/ou representar é natural recusar o que não

\begin{tabular}{l|l|l|l|l|l|l|} 
(C) Rev. digit. bibliotecon. cienc. inf. & Campinas, SP & v.11 & n.1 & p.55-71 & jan./abr. 2013 & ISSN 1678-765X \\
\hline
\end{tabular}


se enquadra nesses movimentos lógicos do raciocínio: tudo que não possui sentido é repelido do nosso pensamento. Fazer sentido ${ }^{4}$ para o pensamento pode depender de parâmetros préconcebidos, ou seja, ter sentido significa que uma informação externa assemelha-se, de alguma maneira, a uma outra informação interna. A relação entre informações externas e internas dependerá de certas heranças ou memórias informacionais constituídas por meio de uma pluralidade de dimensões históricas, sociais e culturais responsáveis pela formação de um complexo estado cognitivo que, em alguns momentos, pode ser chamado de consciência.

Por outro lado, é importante lembrar que ter consciência não significa ver o sentido direto das coisas, pois, como afirma Morin (2005, p.10), existem “[...] princípios ocultos que governam nossa visão das coisas e do mundo sem que tenhamos consciência disso.” Parte-se, então, de uma percepção de mundo "individual” que, direta ou indiretamente, depende de uma cosmovisão que procura traduzir informações que estão ao redor do indivíduo. A tradução de informações externas depende dos níveis de semelhança que a memória informacional de cada indivíduo é capaz de produzir.

A construção do conhecimento está estruturada nessas percepções do mundo, é através delas que se passa a entender os contextos de pensamento contemporâneos. No entanto, é necessário avaliar quais condições epistêmicas são necessárias ao sujeito contemporâneo. Segundo Morin (2005), vivemos um paradigma científico bem peculiar: os princípios de disjunção, de redução e de abstração são máximas dentro do modelo epistêmico e lógico moderno. Existe um domínio das Ciências Naturais, e há certa exclusão das Ciências Humanas e do senso comum, transformando a situação atual em um modelo totalitário onde o conhecimento que não está estruturado em determinados princípios epistemológicos e metodológicos parece ser negado. Boaventura de Sousa Santos acusa a ciência moderna de tomar como pilares sistemáticos e metodológicos a racionalidade existente nas Ciências Exatas e Naturais. Ainda é possível encontrar posturas inflexíveis e dogmatizadoras que estão

\footnotetext{
${ }^{4}$ Segundo Deleuze (2007, p.XV) a teoria do sentido é formada por muitos paradoxos e é difícil separar-se deles, pois, o "[...] sentido é uma entidade não existente, ele tem mesmo com o não-senso relações muito particulares." De forma mais objetiva, mas não menos complexa, a Enciclopédia de termos lógico-filosóficos apresenta o termo "sentido" associado ao termo "referência". Na verdade a associação dos termos serve apenas para destacar a diferença informativa, introduzida por Gottlob Frege (1848-1925), entre duas frases. Por exemplo, "Alceu de Amoroso Lima é Alceu de Amoroso Lima" e "Alceu de Amoroso Lima é Tristão de Ataíde". Em termos de referência as duas frases referem-se à mesma pessoa, mas possuem sentidos diferentes. Os nomes não diferem quanto à referência, mas quanto ao sentido. "Alceu de Amoroso Lima" e "Tristão de Ataíde" referem-se à mesma pessoa, mas não tem o mesmo sentido. Portanto, "[...] a diferença informativa detectada entre as duas frases não se pode explicar unicamente por meio dos nomes 'Tristão de Ataíde' e 'Alceu de Amoroso Lima'. A solução fregiana do problema consiste em defender que, apesar de ambos os nomes não diferirem quanto à referência, diferem quanto ao sentido. O sentido é o modo de apresentação de um objeto associado a um termo,
} nesse caso um nome." (MURCHO, 2006, p.698).

\begin{tabular}{|c|c|c|c|c|c|}
\hline (C) Rev. digit. bibliotecon. cienc. inf. & Campinas, SP & V.11 & n.1 & p.55-71 & ISSN 1678-765X \\
\hline
\end{tabular}


longe do ideal necessário para a estruturação do conhecimento chamado "democrático". (SANTOS, 2010).

As consequências dessa ideia reducionista e dogmática não estão restritas às ciências formais, elas também estão presentes no universo social, com forte impacto sobre a diversidade dos saberes. Para García Gutiérrez, o conceito de verdade, além de dogmático, tornou-se uma obsessão na "gnoseología" ocidental a partir da posição de que uma única verdade é possível. De acordo com o autor, esta posição inflexível "[...] ha permeado todas las instancias de relación entre el sujeto de la enunciación y los entornos que coadyuvan a la reconstrucción constante de su propia subjetividad: contemplación, cognición, memoria, socialización, cultura.” (GARCÍA GUTIÉRREZ, 2007, p.43).

Atualmente, observa-se que as instituições científicas vêm utilizando generalizações grosseiras para persuadir o mundo a valer-se de seus métodos quantitativos e exatos como única via utilizável para todas as demais ciências, caracterizando o paradigma dominante que impõe aquilo que considera exemplar para todos. As Ciências Sociais, e em especial a Ciência da Informação, são prejudicadas por esse tipo de comportamento. Por exemplo, a imposição da lógica clássica como jargão solitário na ciência documental caracteriza um monopólio epistemológico fragmentado, onde a classe dominante, através de suas imposições, dita o que é válido para o mundo, o que é científico ou verdadeiro - obrigações essas que afetam diretamente o indivíduo atual, às vezes sem que ele sequer perceba. Assim, para García Gutiérrez (2007, p.43),

\begin{abstract}
A pesar de tantas certezas incontestables, el sujeto moderno anda apesadumbrado debido a las continuas apariciones de un lado oscuro empeñado en presentar muchos pensamientos y comportamientos, aparentemente racionales, bajo la estela de una, públicamente, anatemizada y abyecta irracionalidad. Pues, en efecto, ante el dilema de la elección de alternativas, el sujeto decide en gran cantidad de ocasiones de forma contraria a como le dicta el sistema de raciocinio en el que ha sido modelado su cerebro, a veces, para sorpresa posterior del propio sujeto.
\end{abstract}

Por outro lado, para García Gutiérrez o mundo não se apresenta tão reduzido e fragmentado como se costuma anunciar: quase toda complexidade organiza-se em uma ordem paradoxal e rizomática, que não pode ser observada por categorias e "estilhaços".

\title{
A lógica opressora e os seus mecanismos de escolha
}

A primeira sistematização da lógica como disciplina foi elaborada por Aristóteles, permanecendo sem alterações substanciais por vários séculos. A partir do séc. XIX matemáticos adicionaram novas características à lógica aristotélica (lógica clássica), passando

\begin{tabular}{|c|c|c|c|c|c|c|}
\hline (c) Rev. digit. bibliotecon. cienc. inf. & Campinas, SP & v.11 & n.1 & p.55-71 & jan./abr. 2013 & ISSN 1678-765X \\
\hline
\end{tabular}


a desenvolver o que ficou conhecida como lógica matemática. Com este novo escopo houve, segundo Krause (2003) e Costa (2008), um desenvolvimento "extraordinário": a lógica passou a ter implicações em diversos campos do conhecimento.

A lógica clássica possui como um de seus princípios básicos a contradição ou nãocontradição. Isto configura a escolha de uma proposição como falsa dentro de um sistema de proposições contraditórias, ou seja: em se tratando de proposições contraditórias, as mesmas não podem ser ao mesmo tempo verdadeiras ou falsas. Por exemplo: $P \wedge \sim P$ (lê-se $P$ e não $P$ ).

Dentro de um sistema lógico clássico esta proposição seria falsa, pois, $P$ não pode existir no mesmo conjunto de sua negação. Esta lógica clássica aristotélica é a mais proeminente nos sistemas de informação atuais, porém, também é usada, por exemplo, na medicina e na informática. A lógica não aceita a complexidade, ou seja, "La unidad lógica es, por excelencia, enemiga de lo diverso" (GARCÍA GUTIÉRREZ, 2007, p.10).

García Gutiérrez diz que ao longo da história da lógica e da epistemologia o que se vê é a imposição de dogmas e repressões em relação ao modo de auto-compreensão (visão interna) e de percepção de mundo (visão externa). Assim,

[...] siendo seres pre-programadamente desesperados ante un mundo extraño que debemos re-elaborar cada día, o de apariencia contradictoria, nos vemos forzados a aceptar el gobierno de una lógica única y universal que niega esa condición constitucional de la diversidad humana. (GARCÍA GUTIÉRREZ, 2007, p.10)

O que torna esta lógica opressora é a condição "humana" em que é aplicada. Essencialmente o ser humano é "plural” e complexo. O paradoxo é um dos princípios do seu ente e, usando um sistema tão preciso e unitário como é o caso da lógica clássica, não seria possível aproveitar todas as formas de conhecimento que são produzidos (e muitas vezes passam despercebidas) no decorrer da sua própria existência. Isto afeta principalmente a construção epistemológica da sociedade, fazendo o indivíduo pensar e construir seu conhecimento em bases meramente "mono-epistêmicas" e simplificadas, que abusam das hierarquizações.

\section{A lógica paraconsistente e os seus mecanismos de contradição}

A lógica clássica, desenvolvida por Aristóteles no século IV a. C., traz dois princípios básicos:

- $\quad$ Princípio do terceiro excluído: $P V \neg P$ (lê-se: Ou este homem é Paulo ou não é Paulo). 
- $\quad$ Princípio da não-contradição: $\neg(P \Lambda \neg P)$, lê-se: não (a terra é redonda e não é redonda), ou seja, uma proposição não pode ser duas coisas ao mesmo tempo.

Contribuições foram feitas à lógica clássica sem que, no entanto, ocorressem alterações substanciais. A matemática, por exemplo, em certa fase incorporou parte dos seus fundamentos. Mas, foi apenas "Entre 1910 e 1913 [que] o lógico polonês Jean Lukasiewicz (1876-1956) e o lógico russo Nicolai Vasiliev (1880-1940) chamaram a atenção, de forma independente, para o fato de que [...] alguns princípios da lógica aristotélica poderiam ser revisados, inclusive o da contradição.” (KRAUSE, 2003).

Porém, ainda de acordo com Krause, Lukasiewicz não elaborou teorias profundas sobre a problematização da contradição, apenas limitou-se a analisar criticamente esses princípios. Em 1948, um dos discípulos de Lukasiewicz, chamado S. Jaskowski, apresentou uma lógica que utilizava a contradição. Sistema que ficou conhecido como lógica discussiva ou discursiva. Contudo, ele se ateve apenas a uma parte da lógica: o cálculo proposicional. Apenas na década de 1950 foi que o matemático, lógico e filósofo brasileiro Newton Carneiro Affonso da Costa desenvolveu a lógica paraconsistente.

A lógica paraconsistente traz, no escopo do seu estudo sobre os cálculos proposicionais, três condições primordiais. São elas:

(i) $\mathrm{O}$ princípio da contradição, na forma $\neg(\mathbf{A} \wedge \neg \mathbf{A})$, não deveria ser válido em geral;

(ii) De duas premissas contraditórias $\mathbf{A}$ e $\neg \mathbf{A}$, não deveríamos deduzir qualquer fórmula $\mathbf{B}$;

(iii) Eles deveriam conter os mais importantes esquemas e regras da lógica clássica compatíveis com as duas primeiras condições. (D’OTTAVIANO; FEITOSA, 2003, p. 27.).

Embora a lógica paraconsistente negue um dos princípios básicos da lógica clássica, adequando-se ao conjunto de lógicas não-clássicas heterodoxas, Costa (2008) afirma que a lógica paraconsistente não tem o objetivo de anular ou substituir a lógica aristotélica, apenas não pode ser usada em determinadas situações. Como seria o caso das teorias físicas contraditórias, onde há teorias que, embora provadas existencialmente, contradizem uma a outra.

A lógica paraconsistente permite o suporte efetivo da contradição. Diferentemente da lógica clássica, a lógica paraconsistente não torna o sistema de proposições trivial - situação que seria inviável dentro de um sistema lógico clássico. Um exemplo básico disso seria: $O$ homem é surdo, mas escuta. Na lógica clássica um indivíduo que escuta seria um não-surdo e, sendo assim, segundo a lei do terceiro excluído, jamais poderia ser surdo. Já na lógica

\begin{tabular}{l|l|l|l|l|l|l} 
(C) Rev. digit. bibliotecon. cienc. inf. & Campinas, SP & v.11 & n.1 & p.55-71 & jan./abr. 2013 & ISSN 1678-765X \\
\hline
\end{tabular}


paraconsistente este homem poderia ser surdo e, no entanto, ouvir em determinadas situações ou dependendo de determinados fatores. A lógica paraconsistente permite alcançar parâmetros e situações que a lógica clássica simplesmente nega a existência, aceitando o contexto onde se encontra a proposição, pois na lógica paraconsistente existe a perda do binarismo presente na lógica clássica.

O princípio da não-contradição vem sendo discutido em vários domínios das ciências contemporâneas: isto está refletido na recorrente incorporação da lógica paraconsistente em sistemas de informação para tomada de decisão em diversas áreas, seja, como já indicamos, na Medicina (em diagnósticos médicos e manipulação de banco de dados), na Engenharia de Produção (representada pelo algoritmo para-analisador), na Psicologia (em pesquisas sobre cognição), na Robótica e Inteligência Artificial (especificamente na construção de redes neurais artificiais), permeando campos como as Ciências Sociais, em especial a Ciência da Informação ${ }^{5}$. Ainda na noção de binarismo e usando o recorte das Ciências Sociais, Edgar Morin aponta algumas características da ciência clássica que condiz com o paradigma lógico aristotélico:

O princípio de explicação da ciência clássica via no aparecimento de uma contradição o sinal de um erro de pensamento e supunha que o universo obedecia à lógica aristotélica. As ciências modernas reconhecem e enfrentam as contradições quando os dados apelam, de forma coerente e lógica, à associação de duas ideias contrárias para conceber o mesmo fenômeno (a partícula que se manifesta quer como onda, quer como corpúsculo, por exemplo). (MORIN, 2002, p. 29).

Isto pode indicar a mudança do contexto epistemológico atual, onde caminha-se de um sistema fechado e binário, como é o caso da ciência aristotélica, para um novo paradigma científico, que trata da contradição como um elemento de ligação, promovendo um novo enlace para ideias que antes não eram aceitas. No entanto, embora esse reconhecimento de ideias contraditórias na ciência contemporânea seja um ponto positivo para a epistemologia, devemos salientar que a realidade global da racionalidade científica que surge no século XVIII e afeta as Ciências Sociais no século XIX

[...] admite variedade interna mas que se distingue e defende, por via das fronteiras ostensivas e ostensivamente policiadas, de duas formas de conhecimento não científico (e, portanto, irracional) potencialmente perturbadoras e intrusas: o senso comum e as chamadas humanidades ou estudos humanísticos [...]. (SANTOS, 2010, p.21).

\footnotetext{
${ }^{5}$ Ver, por exemplo, a tese de doutorado de Carlos Alberto Corrêa "Indexação automática e visualização de informações: um estudo baseado em Lógica paraconsistente”. (CORRÊA, 2011).

\begin{tabular}{l|l|l|l|l|l|l}
\hline (C) Rev. digit. bibliotecon. cienc. inf. & Campinas, SP & v.11 & n.1 & p.55-71 & jan./abr. 2013 & ISSN 1678-765X \\
\hline
\end{tabular}
}


A obsessão para atingir o rigor científico usa esses parâmetros como barreiras epistemológicas entre as duas tipologias de conhecimento, ou até mesmo argumenta contra o chamado conhecimento do senso comum.

No campo da Ciência da Informação, parece que alguns trabalhos de García Gutiérrez são influenciados pelo estudo das "novas" lógicas, principalmente na linha que ele chama "desclassificação". García Gutiérrez sai em defesa dos elementos contraditórios como construtos para a verdade e, por assim dizer, uma verdade mais justa para todos os indivíduos e em sintonia com o contexto epistemológico. Talvez, o uso de um sistema lógico deste tipo refletiria (dentro e fora de um sistema de classificação) algumas das características essenciais do homem: cultura, memória, modo de encarar o mundo - enfim, a pluralidade proeminente na existência humana.

De acordo com García Gutiérrez (2007, p.54), "La lógica paraconsistente admite que un enunciado sea contradicho desde su interior." Porém, como visto com Costa (2008), a lógica paraconsistente não anula a lógica clássica, apenas acrescenta uma nova característica àquela já existente, quebrando a sua rigidez monopolizadora.

A contradição não é um elemento contrário à verdade. Dentro de um sistema lógico clássico o oposto da verdade é a falsidade. García Gutiérrez (2007, p.58) defende uma tipologia de contradições baseada em elementos paraconsistentes repelindo a ideia classificatória atual, pois, sendo assim, “[...] habría de ser, ésta, una tipología relativa, abierta e concorde con la 'logica' de la misma sustancia que pretende 'ordenar'." Neste caso, a contradição seria o mecanismo classificatório propulsor de ideias plurais, que resultaria em conhecimentos convergentes e que seriam explorados em diversas esferas, de forma lícita e democrática - alterando não só os sistemas classificatórios, mas também a percepção e a liberdade de novas ideias.

\section{EPISTEMOGRAFIA INTERATIVA}

Algumas ciências que ainda cultivam princípios positivistas descontextualizados e que ainda acreditam que a técnica é um caminho auto-suficiente pretendem alcançar a objetividade dos seus conceitos unicamente por meio da especificidade e da imposição de limites ao conhecimento.

O modelo epistemológico dessas ciências está fundamentado na regra equivocada e atrasada de que é necessário criar barreiras rígidas entre os saberes e os não saberes. Isto é, os saberes ou os conhecimentos são "produtos" exclusivos do isolamento e da

\begin{tabular}{|l|l|l|l|l|l|l} 
(C) Rev. digit. bibliotecon. cienc. inf. & Campinas, SP & v.11 & n.1 & p.55-71 & jan./abr. 2013 & ISSN 1678-765X \\
\hline
\end{tabular}


superespecialização. Por outro lado, diante das barreiras que são criadas, é necessário analisar que contribuições esse ato traz ao conhecimento, seja ele científico ou do senso comum.

Desse modo, a epistemografia ${ }^{6}$ surge com o objetivo de resgatar e reabilitar os conhecimentos "subalternos", diferenciando-se, assim, dos paradigmas epistemológicos habituais.

A epistemografia ou epistemografia interativa configura-se como uma organização horizontal e interativa dos conhecimentos que adota uma estrutura rizomática, ou seja, os conhecimentos estão sempre buscando uma relação, um sentido. Como afirma García Gutiérrez (2008, p.42), “[...] é na interação [...] onde residem o sentido, a cultura, o conhecimento e a memória."

Assim, a partir desse pressuposto de conexão entre os conhecimentos, García Gutiérrez desenvolve o termo "epistemografia interativa" com base na ideia de "epistemologia prática" (termo designado por Jean Claude Gardin). A epistemografia interativa vem com a necessidade de agrupar uma visão de valor e ética capaz de acolher os conhecimentos excluídos e possibilitar a sua inclusão nas redes digitais onde, também, percorrem os conhecimentos dominantes, devolvendo-lhes a legitimidade "perdida" nos processos tradicionais e dominantes de concepção e de organização do conhecimento. (GARCÍA GUTIÉRREZ, 2006; 2011).

A epistemografia interativa pode ser entendida como uma nova corrente transdisciplinar que abriga os conhecimentos excluídos, representando-os numa multiplicidade de culturas e discursos como em uma organização horizontal. Também pode definir-se como um fluxo transdisciplinar, pois, traz uma nova prática representativa de mútuas interações entre os conceitos, onde os mesmos estão sempre em movimento, possibilitando a construção de um novo paradigma unificador.

É possível dizer, portanto, que a inserção desses conhecimentos na rede digital funcionaria como forma de sobrevivência e uma alternativa de integração nas redes digitais com a possibilidade de auto-desenvolvimento.

\footnotetext{
${ }^{6}$ Nas palavras de García Gutiérrez (2006, p.105), a epistemografia "[...] tem suas raízes em disciplinas positivistas como a Biblioteconomia ou a Museologia, das quais luta por se libertar." Para o autor, a formação contínua em matérias como a gnosiologia, a neurociência, a teoria e economia política, os estudos culturais e pós-coloniais, as teorias feministas, dentre outras, ajudariam o epistemógrafo a se "libertar" do fundamento positivista.
}

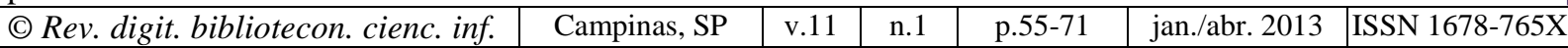




\section{EXOMEMORIA, MULTICULTURALISMO E MEDIAÇÃO}

Entendemos por memória o registro, a conservação e a restituição de ideias, pensamentos e imagens, que podem ser readquiridos. Poder-se-á considerar a memória como uma das formas de identificação própria do mundo, afinal parte do desenvolvimento humano sempre se deu pela constante busca por uma memória expandida. A memória nada mais é do que uma extensão da biomemória que possui como principal mecanismo seletivo o próprio esquecimento ou o esquecimento próprio. A invenção da escrita é até hoje uma das realizações mais bem sucedidas da humanidade. Desde a sua invenção ainda é o veículo mais usado para registro da memória. No entanto, a memória precisa organizar-se de forma que todas as "categorias" sejam compreensíveis a todos, distinguindo o que é realmente memória e o que é imaginação.

Em sua origem grega, o conceito de memória estava ligado a algo totalmente sobrenatural, um "dom" a ser praticado. A memória era uma experiência interior, vista como sinônimo de imaginação (RICOUER 1996 apud SILVA, 2002). Para Rosário (2002), a memória é imortal e não está apenas no nosso passado quando recordamos de algo, mas está presente, no idioma, no que temos e no que esperamos: a memória é a nossa "identificação". Pimenta (2005) diz que a memória é a "chave" para todo o desenvolvimento humano, pois, está relacionada com as ações políticas, com o conhecimento, com a cultura e com a tradição.

Afinal, a memória é um "espaço na mente" capaz de depositar e recuperar ideias ou imagens, onde os fragmentos de memória se ligam à cosmovisão do indivíduo para gerar novos conhecimentos.

A memória não é só uma construção individual, mas, também, ela é coletiva e social. O indivíduo adquire valores, normas e crenças de um dado grupo de pessoas e deste modo parte da memória coletiva é estabelecida pelos grupos sociais. A memória coletiva pode também ser chamada de memória social, pois, ela é construída a partir de um conhecimento comunitário associado à cultura, aos costumes e às crenças de um povo.

Maurice Halbawchs afirma, em seu livro A memória coletiva, que a memória de um indivíduo não é apenas sua, mas também é uma dimensão adquirida que ultrapassa o plano individual e, uma vez que nenhuma memória acontece fora da sociedade, toda memória passa a ser coletiva. (HALBWACHS, 2009). Com base em Todorov, García Gutiérrez apresenta dois "tipos" de memória: memória literal e memória exemplar. A memória literal "preserva" e recupera fatos e acontecimentos na forma em que foram registrados, já a memória exemplar 
recuperada "experiências" sobre fatos e acontecimentos. A reconstrução das memórias coletivas esbarra, segundo García Gutiérrez (2008), nos resquícios de domínio que prevalecem sobre as experiências de uma comunidade ou povo. Na perspectiva dominante o conhecimento produzido a partir das experiências coletivas é "dispensável” e ocultado em periferias do saber e do conhecimento.

Por outro lado, os conhecimentos periféricos ou "marginais" estão cada vez mais visíveis a partir de novos formatos de informação que permitem a exteriorização e a comunicação das memórias coletivas. Assim, exomemórias seriam as memórias exteriorizadas que passam despercebidas, abrangendo toda informação registrada - pensamentos, experiências, fotografias, revistas, multimídia - seja em suporte físico ou digital, conhecimentos ou lembranças (GARCÍA GUTIÉRREZ, 2006, p.104), sem privilegiar determinadas áreas ou discursos, incluindo os conhecimentos culturais, populares e artísticos.

A construção da exomemória surge a partir dos preconceitos locais e globais com os conhecimentos que fogem da ordem pré-estabelecida. Por esse motivo é necessário o "desvelamento" dessas ideias pré-concebidas com o intuito de construir uma memória democrática e mista. Embora o conceito de exomemória esteja normalmente vinculado ao digital, não se limita a ele, pois, documentos de todos os tipos constituem a exomemória.

O universo digital, em toda a sua extensão, possui uma estrutura interligada de redes que amplifica as exomemórias, refletindo rapidez e uma possível democratização nas trocas de informações e na geração de novos conhecimentos. Com as redes surge a possibilidade de utilização de um novo processo classificatório e de comunicação horizontal, possibilitando uma forma multidirecional e interativa dos conhecimentos que traz a tona o conceito de Inteligência Coletiva (LÉVY, 2007) - fomentada por trocas de informações e de conhecimentos à distância, por grupos de pessoas (comunidades) em um espaço interativo onde tudo passa a ser de "muitos para muitos".

O campo híbrido da cultura pode ser chamado de um ambiente "multicultural" de interação que antecede as redes digitais e, portanto, tem uma história que pode ser contada por meio de eventos diversos que vão de políticas globais e locais aos artefatos de um grupo. (GEERTZ, 2006; GARCÍA CANCLINI, 2003; BURKE, 2003). Para García Gutiérrez, apesar de o multiculturalismo apresentar uma ideia de "quantificação", é quase impossível numerar, qualificar ou demarcar culturas que não se sabe como e onde começam ou como e onde terminam: "Sabemos o que é e onde acaba a cultura espanhola, que limites tem a cultura catalã, europeia ou ocidental? Podemos inventariar e purificar taxonomias culturais, indicando 
com nitidez seus componente e fronteiras?” (GARCÍA GUTIERREZ, 2008, p.73). Em sua complexidade, portanto, o multiculturalismo é uma nova identidade cultural, social, ou até mesmo política capaz de trazer para o conhecimento uma nova abordagem.

Se há uma nova forma de conhecer também há uma nova forma de mediar o conhecimento. Então, surge a pergunta: como mediar toda essa exomemória, multicultural, multidirecional e multidisciplinar? Nas práticas de mediação da exomémoria vemos novamente a influência do positivismo na formação dos profissionais organizadores do conhecimento que detêm o conhecimento fazendo uso de uma linha divisória e não de uma linha onde os conhecimentos podem se interligar. O uso desta linha divisória pode ser visto na clássica hierarquização da árvore de Porfírio, na lógica demarcacionista "[...] baseada mais em conceitos que afastam (fencing-concepts) que em conceitos que ligam (linking-concepts)" (GARCÍA GUTIÉRREZ, 2008, p.45), separando o puro saber cientifico dos conhecimentos de senso comum.

A demarcação, para García Gutiérrez, em seu significado não é negativa, mas se aplicada intencionalmente, separa, distingue e determina. Porém, a utilização desse conceito dentro da classificação dos conhecimentos é avaliada como agressiva, uma vez que se fundamenta em princípios hierárquicos e totalitários. Na mediação da exomemória é necessário levar em conta a linguagem a ser utilizada, que deve ser organizada em torno do usuário, daquele que faz a pesquisa e usa a informação, buscando um "meio termo" entre a linguagem natural do usuário multicultural e a linguagem não-natural do sistema unidirecional.

\section{CLASSIFICAR OU DESCLASSIFICAR PARA CONHECER?}

A classificação sistematiza o conhecimento por meio de códigos "culturais" que estão na base da linguagem, das percepções, das técnicas e dos costumes. Classificar tange atividades como descrição, hierarquização, ordenação, agrupamento por semelhanças, separação por diferenças, (des)fragmentação do saber. A essência da teoria da classificação está fundamentada em uma lógica clássica "inflexível”, muito embora, de acordo com García Gutiérrez (2007, p.6), a cosmovisão dos indivíduos "glocais" - de "glocalidade", neologismo que indica a simultaneidade dos indivíduos de mundos diferentes - modifique-se constantemente, sempre se adequando aos diversos contextos e situações precedentes de sua condição contraditória. 
Mesmo com todas as vantagens evidentes nos sistemas de classificação, é notável também a existência de uma dicotomia que permeia desde a naturalidade à arbitrariedade, aspectos que são discutidos até pelos próprios propulsores da temática, como Buffon quando reflete sobre o método perfeito da classificação da História Natural:

\begin{abstract}
[...] é impossível dar um sistema geral, um método perfeito, não somente para totalidade da história natural como mesmo para um só dos seus ramos pois, para fazer um sistema, um arranjo, numa palavra, um método geral, é necessário que tudo aí esteja compreendido; é necessário dividir esse todo em diferentes classes, dividir essas classes em gêneros, subdividir os gêneros em espécies, e tudo isso seguindo uma ordem na qual entra necessariamente o arbitrário. (BUFFON, 1749 apud POMBO, 1998, p. 9).
\end{abstract}

Desse modo a classificação desempenha um papel de delimitação do saber, onde a utopia da organização do conhecimento é regulada por meio da fixação de limites, excluindo sumariamente partes consideradas “difusas", aparentemente “imperceptíveis" e marginalizadas. Sob esse ponto de vista é necessário refletir a respeito das perspectivas atuais e projeções acerca da construção e organização dessas memórias, pois

\footnotetext{
Perdeu-se já quase definitivamente a possibilidade de reconstruir a memória social humana sob pontos de vista incômodos para os poderes do passado [...] uma vez que mesmo os vestígios e sinais mais abundantes são aqueles deixados pelas classes dominantes ou pelos poucos privilegiados treinados na arte da escrita [...] Diante de tamanho entulho do poder, só poderemos construir uma hermenêutica arqueológica da memória realmente digna incorporando [...] a outros métodos. (GARCÍA GUTIÉRREZ, 2008, p. 52).
}

Os instrumentos classificatórios são utilizados na organização da memória, contudo o conceito de memória também se relaciona com a ideia de coletivo, onde vários indivíduos participam diretamente dessa construção. A partir disso deve-se salientar que com a utilização dos sistemas classificatórios estaríamos fragmentando e excluindo as partes "imperceptíveis" da memória, fragmentos marginalizados e dispensáveis ao dogmatismo do dominador. Diante desse paradigma dominante e excludente surge, como já dissemos, a ideia de uma construção horizontal do conhecimento não apenas subalterno, mas onde todos os conhecimentos dominantes e participantes interagem entre si, formando uma estrutura de rede.

O conceito de exomemória poderia ser amplamente posto em prática diante dessa nova proposta de organização do conhecimento horizontal na rede, provendo um novo paradigma condizente com a realidade atual do conhecimento, pois, apesar de estarmos inseridos ainda nos tradicionais ambientes do saber (que por si só refletem uma complexidade incompatível com a visão simplista da classificação), a mudança nesses espaços, pelas vias da web é evidente, transformando a apropriação e a construção do conhecimento. As ideias de 
compartilhamento, multidirecionamento, proliferação, pluralismo, cibercultura e interatividade formam a nova estrutura do conhecimento, o que já impossibilitaria o uso de instrumentos classificadores descontextualizados.

Não se trata de uma problemática recente, visto que os sistemas de classificação são sistemas, de base lógico-formal, construídos com a finalidade de organizar e controlar o conhecimento. A questão principal é que o conhecimento está mudando e suas formas de controle já não parecem se adequar às características, que hoje, estão em evidência. Em outros tempos pode ser que esforços seriam realizados para adaptar os conhecimentos emergentes às categorias fixas, porém, não é possível realizar tamanho exercício de redução lógica devido ao espaço que os conhecimentos "deslegitimados" conquistaram na atualidade. Nesse ponto, a epistemografia interativa propõe " [...] um conjunto de categorias tecnoculturais, facilitando assim a integração de indivíduos e intercâmbios horizontais entre culturas, que periodicamente terão de ser validadas por categorias éticas elaboradas na transcultura (GARCÍA GUTIÉRREZ, 2008, p. 56, grifo do autor).

Ou seja, um sistema (des)classificatório que permite a existência de todos os sentidos possíveis e não um único conceito ordenado e dogmático fixado pelas instâncias dominantes do poder. Além disso, a contradição seria incorporada e validada pela lógica paraconsistente, acrescentando novas formas de inter-relação e pluri-ordenação traduzindo inovações na configuração da classificação do conhecimento.

\section{CONSIDERAÇÕES FINAIS}

Diante das questões levantadas, dos novos conceitos alçados por García Gutiérrez que foram abordados e discutidos ao longo do texto, é quase impossível não ser levado a repensar as práticas atuais de classificação. No entanto, deve-se pensar também nas consequências de uma mudança desses parâmetros atuais, pois, as categorias tradicionais de classificação ainda são os principais elementos na estrutura dos conhecimentos e dos saberes hoje organizados e disponíveis.

As discussões impulsionadas por meio das novas configurações do conhecimento estão em pleno desenvolvimento e já demonstram alguns resultados, especialmente nos campos da lógica de organização e da epistemologia de legitimação dos saberes.

Já existem iniciativas de flexibilização dos sistemas rígidos a partir de modelos baseados amplamente em contextos de produção e apropriação do conhecimento. Tais modelos têm 
como objetivo não apenas equilibrar a balança entre sistema e usuário, mas também absorver o próprio conhecimento que é produzido em ambientes a que se destina.

Dito de outro modo, a lógica de organização passa por análises que visam dinâmicas dos conhecimentos, pois, o momento atual da ciência tende a entender que o universo do conhecimento é muito mais complexo e rico do que os limites epistemológicos firmados visando progresso e autonomia.

Não há, evidentemente, progresso sem autonomia, porém, a decisão de firmar quais conhecimentos servem ao progresso e quais são autônomos deixou a herança de que saberes desvinculados são saberes especiais e consistentes.

Portanto, é necessário entender que novas formas de conhecimento estão emergindo, que existem alternativas lógicas e epistemológicas que podem se deslocar dos núcleos para as áreas de interface, que a complexidade dos movimentos multiculturais é muito maior do que se imaginava, pois, os nomes são recentes, mas, os movimentos também têm sua história e as iniciativas de resistência são concomitantes às iniciativas de domínio. Enfim, é preciso o reestabelecimento do conceito de revolução a partir de um novo modelo teórico que recupere o diálogo histórico do conhecimento, vinculando ausências e presenças.

\section{REFERÊNCIAS}

BURKE, Peter. Hibridismo cultural. Tradução Leila Souza Mendes. Rio Grande do Sul: UNISINOS, 2003.

CORRÊA, Carlos Alberto. Indexação automática e visualização de informações: um estudo baseado em lógica paraconsistente. 2011. 152f. Tese (Doutorado em Ciência da Informação) - Escola de Comunicações e Artes, Universidade de São Paulo, São Paulo, 2011.

COSTA, Newton Carneiro Affonso da. Paixão e contradição. Pesquisa Fapesp, São Paulo, n.148, jun. 2008. Entrevista concedida a Neldson Marcolin. Disponível em:

<http://revistapesquisa2.fapesp.br/?art=3536\&bd=1\&pg=1\&lg $\Rightarrow$ Acesso em: 29 fev. 2012.

DELEUZE, Gilles. Prólogo: de Lewis Carroll aos Estóicos. In: Tradução Luiz Roberto Salinas Fortes. 4. ed. São Paulo: Perspectiva, 2007.

Lógica do sentido.

D'OTTAVIANO, Ítala Maria Loffredo; FEITOSA, Hércules de Araújo. Sobre a história da lógica, a lógica clássica e o surgimento das lógicas não-clássicas. 2003. Disponível em: <ftp://ftp.cle.unicamp.br/pub/arquivos/educacional/ArtGT.pdf>. Acesso em: 08 ago. 2011.

GARCÍA CANCLINI, Néstor. Culturas híbridas: estratégias para entrar e sair da modernidade. Tradução de Ana Regina Lessa e Heloísa Pezza Cintrão. 4. ed. São Paulo: EDUSP, 2003. 
GARCÍA GUTIÉRREZ, Antonio. Cientificamente favelados: uma visão crítica do conhecimento a partir da epistemografia. Transinformação, Campinas, v.18, n.2, p.103-112, maio/ago. 2006.

GARCÍA GUTIÉRREZ, Antonio. Desclasificados: pluralismo lógico y violencia de la clasificación. Barcelona: Anthoropos, 2007.

GARCÍA GUTIÉRREZ, Antonio. Epistemología de la documentación. Barcelona: Stonberg, 2011.

GARCÍA GUTIÉRREZ, Antonio. Outra memória é possível: estratégias descolonizadoras do arquivo mundial. Petrópolis: Vozes, 2008.

GEERTZ, Clifford. O saber local: novos ensaios em antropologia interpretativa. Tradução Vera Mello Joscelyne. 8. ed. Petrópolis, RJ: Vozes, 2006.

HALBWACHS, Maurice. A memória coletiva. Tradução Beatriz Sidou. 2. ed. São Paulo: Centauro, 2009.

KRAUSE, Décio. Lógica paraconsistente. Crítica, 23 nov. 2003. Disponível em: 〈http://criticanarede.com/log_paraconsistente.html〉. Acesso em: 10 ago. 2011.

LÉVY, Pierre. A inteligência coletiva: por uma antropologia do ciberespaço. Tradução Luiz Paulo Rouanet. 5. ed. São Paulo: Loyola, 2007.

MORIN, Edgar. Ciência com consciência. Tradução de Maria D. Alexandre e Maria Alice Sampaio Dória. 6. ed. Rio de Janeiro: Bertrand Brasil, 2002.

MORIN, Edgar. Introdução ao pensamento complexo. Tradução Eliane Lisboa. Porto Alegre: Sulina, 2005.

MURCHO, Desidério. Sentido/Referência. In: BRANQUINHO, João; MURCHO, Desidério; GOMES, Nelson Gonçalves. (Ed.) Enciclopédia de termos lógico-filosóficos. São Paulo: Martins Fontes, 2006.

PIMENTA, Ricardo Medeiros. Conhecer para esquecer. A identidade e os caminhos para a memória: perspectivas nietzschianas sobre a identidade e o esquecimento como elementos constitutivos da memória no lócus social. Morpheus - Revista eletrônica em Ciências Humanas, Rio de Janeiro, n.6, 2005. Disponível em <http://www.unirio.br/morpheusonline/Ricardo\%20Pimenta.htm> Acesso em: 16 fev. 2012.

POMBO, Olga. Da classificação dos seres à classificação dos saberes. Leituras - Revista da Biblioteca Nacional de Lisboa, n.2, p.19-33, primavera, 1998.

ROSÁRIO, Claúdia Cerqueira do. O lugar mítico da memória. Morpheus - Revista eletrônica em Ciências Humanas, Rio de Janeiro, ano 1, n. 1, 2002. Disponível em: <http://www.unirio.br/morpheusonline/Numero01-2000/claudiarosario.htm> Acesso em: 14 fev. 2012.

\begin{tabular}{l|l|l|l|l|l|l|} 
(C) Rev. digit. bibliotecon. cienc. inf. & Campinas, SP & v.11 & n.1 & p.55-71 & jan./abr. 2013 & ISSN 1678-765X \\
\hline
\end{tabular}


SANTOS, Boaventura de Sousa. Um discurso sobre as ciências. 7. ed. São Paulo: Cortez, 2010.

SILVA, Helenice Rodrigues da. "Rememoração"/comemoração: as utilizações sociais da memória. Revista Brasileira de História, v.22, n. 44, p. 425-438, 2002. Disponível em: <http://dx.doi.org/10.1590/S0102-01882002000200008>. Acesso em: 12 set. 2011.

Como citar este artigo:

SOARES, Maria Sueny Barbosa; MARTINS, Mariana Thamires; FRANCELIN, Marivalde Moacir. Pluralismo lógico e epistemografia interativa como ferramentas desclassificadoras do conhecimento. Rev. digit. bibliotecon. cienc. inf., Campinas, SP, v.11, n.1, p.55-71, jan./abr. 2013. ISSN 1678765X. Disponível em: <http://www.sbu.unicamp.br/seer/ojs/índex.php>. 